\title{
Pegylated Interferon for Treatment of Chronic Hepatitis C in Hemodialysis Patients in Croatia
}

\author{
Nikolina Basic-Jukic ${ }^{a} \quad$ Marijana Gulin ${ }^{b}$ Jasna Slavicek ${ }^{a}$ \\ Valentina Coric-Martinovic ${ }^{c}$ Bosiljka Iskra $^{d}$ Sanjin Racki ${ }^{e}$ Milenka Sain ${ }^{f}$ \\ Rajko Ostojićg Irena Hrstic ${ }^{g}$ Dragan Ljutic ${ }^{f}$ Boris Vucelic ${ }^{g}$ Petar Kes ${ }^{a}$ \\ aDepartment of Nephrology, Arterial Hypertension and Dialysis, University Hospital Centre Zagreb, \\ School of Medicine, University of Zagreb, Zagreb, b Department of Dialysis, General Hospital Sibenik, Sibenik, \\ 'Department of Dialysis, General Hospital Vinkovci, Vinkovci, dDepartment of Dialysis, General Hospital Virovitica, \\ Virovitica, ${ }^{e}$ Department of Nephrology and Dialysis, University Hospital Centre Rijeka, Rijeka, ${ }^{\text {fDepartment of }}$ \\ Nephrology, University Hospital Split, Split, and 9Department of Gastroenterology, University Hospital Centre \\ Zagreb, School of Medicine, University of Zagreb, Zagreb, Croatia
}

\section{Key Words}

Hepatitis C · Dialysis · Pegylated interferon • Outcome •

Renal transplantation

\begin{abstract}
Background and Aims: Hepatitis C virus (HCV) infection is a frequent complication among long-term dialysis patients. The aim of the present study was to evaluate the efficacy and side effects of pegylated interferon- $\alpha_{2 a}$ (PEG-IFN- $\alpha_{2 a}$ ) treatment in hemodialysis patients. Methods: We retrospectively reviewed charts of 16 HCV-RNA-positive hemodialysis patients. Results: There were 11 male and 5 female patients treated with dialysis for 6-28 years. Twelve patients had HCV genotype 1b, 2 patients had $3 a$, and 1 patient had genotype $2 a$. Although only 10 out of 16 patients completed 48 weeks of treatment, early virological response and end-of-treatment virological response were achieved in 9 and 13 patients, respectively. Sustained virological response was recorded in 9 patients. The most common side effect was anemia. A flu-like syndrome was documented in 6, myalgia in 4, and arthralgia in 5 patients. Rectorrhagia, endocarditis and severe cough were recorded in
\end{abstract}

1 patient each. Nine patients received a renal transplant, and all 6 responders remained HCV-RNA-negative. Conclusions: PEG-IFN- $\alpha_{2 a}$ has limited efficacy in dialysis patients. A significant proportion of patients discontinued treatment because of side effects. Additional studies with long-term follow-up are needed to determine the optimal treatment of HCV infection in the dialysis population.

Copyright $\odot 2011$ S. Karger AG, Basel

\section{Introduction}

Liver disease caused by hepatitis C virus (HCV) causes significant morbidity and mortality among patients with end-stage renal disease (ESRD) $[1,2]$. The disease is considered as slowly progressive in dialysis patients, but the major problem with $\mathrm{HCV}$ infection occurs after renal transplantation. Immunosuppressive drugs may significantly increase viral load after renal transplantation, thus possibly accelerating hepatic pathology [3]. In some cases, hepatic lesions may progress to cirrhosis and hepatocellular carcinoma.

\section{KARGER}

Fax +41613061234 E-Mail karger@karger.ch www.karger.com
Nikolina Basic-Jukic, $\mathrm{MD}, \mathrm{PhD}$

Department of Nephrology, Arterial Hypertension and Dialysis

University Hospital Centre Zagreb, School of Medicine, University of Zagreb

Kispaticeva 12, HR-10000 Zagreb (Croatia)

Tel./Fax +385 12312 517, E-Mail nina_basic@ net.hr 
Treatment with interferon (IFN) after renal transplantation is contraindicated because of the risk of acute rejection. For this reason, HCV infection in patients with ESRD should be treated before renal transplantation. IFN- $\alpha_{2 a}$ monotherapy has better results but relatively poor tolerance in dialysis patients compared to patients with normal renal function $[4,5]$. A modified form of IFN- $\alpha$, pegylated IFNa or peginterferon alpha (PEGIFN- $\alpha$ ), was developed by attaching a polyethylene glycol moiety to IFN- $\alpha$. Reduced renal and cellular clearance and decreased immunogenicity of the protein were achieved. These effects prolong the half-life of the drug, what enables once-weekly dosing [6].

Standard treatment for HCV patients with normal renal function is a combination of PEG-IFN- $\alpha$ and ribavirin [1]. Ribavirin is a nucleoside analog with antiviral activity [7, 8]. It decreases HCV infectivity in a dose-dependent manner [9]. Several reports have demonstrated that ribavirin may be used in dialysis patients but with great caution [10]. The ribavirin dose needs to be significantly reduced, plasma concentrations should be closely monitored, and the erythropoietin dose should be increased to compensate for hemolytic anemia associated with the use of ribavirin.

Data on treatment of dialysis patients with PEG-IFN$\alpha$ is still scarce. We present results of treatment with PEG-IFN- $\alpha_{2 \mathrm{a}}$ in dialysis patients in Croatia.

\section{Patients and Methods}

To the best of our knowledge, all patients treated with PEGIFN- $\alpha_{2 a}$ who completed treatment in Croatia were included in the investigation. Data were collected retrospectively from data records and medical files. Time on dialysis, age, gender, HCV-RNA status, HCV genotype, liver chemistries and liver biopsy results were recorded. Treatment outcome was followed at 3, 6 and 12 months by reverse transcription polymerase chain reaction (RT-PCR). Physicians responsible for the treatment of patients reported side effects. PEG-IFN- $\alpha_{2 a}$ dose, blood transfusions, and erythropoietin dose were recorded, as well as results of pathohistological evaluation of samples obtained by percutaneous liver biopsy (if performed).

Patients underwent chronic bicarbonate hemodialysis for treatment of ESRD three times weekly. All patients were evaluated before treatment with PEG-IFN- $\alpha_{2 a}$ to exclude pregnancy, autoimmune, thyroid, psychiatric or malignant disease. All patients were HIV- and HBV-negative. Patients were not previously treated with IFN.

HCV-RNA expression was determined by RT-PCR (Cobas Amplicor; Roche, New York, N.Y., USA). The lower detection limit of the test was 600 copies $/ \mathrm{ml}$.

Complete blood count was checked once a week before treatment with PEG-IFN- $\alpha_{2 \mathrm{a}}$. PEG-IFN- $\alpha_{2 \mathrm{a}}$ (Pegasyse, Roche) was administered once a week at a dose of $135 \mu \mathrm{g}$ subcutaneously at the end of the dialysis session. Dose reduction or discontinuation was performed by the treating physician, based on treatment response, clinical status and laboratory parameters.

Therapeutic response (virological and biochemical) was determined after 12 weeks of treatment. At least a 2-log decline from the pretreatment HCV-RNA level was considered as a positive early virological response (EVR), and treatment was continued for an additional 36 weeks.

Biochemical response was defined as normalization of the serum ALT value. EVR was defined as negative HCV-RNA or a 2-log decrease after 12 weeks of treatment, while end-of-treatment virological response (ETVR) was defined as negative HCVRNA after the end of PEG-IFN- $\alpha_{2 a}$ therapy. Six months after completion of therapy, sustained virological response (SVR) was determined. Data are presented as means and SD, or percentages. SPSS version 17.0 was used for statistical analysis.

\section{Results}

\section{Patients' Characteristics}

There were 11 male and 5 female patients aged 34-62 years (average 51.06 years) treated with dialysis for 6-28 years (average 19.25 years). Twelve patients had HCV genotype $1 \mathrm{~b}, 3$ patients had $3 \mathrm{a}$, and 1 patient had genotype 2a. The number of HCV-RNA copies determined by $\mathrm{PCR}$ ranged from $2.27 \times 10^{4}$ to $7.78 \times 10^{6}$. Five patients had positive HCV-RNA determined by PCR, but unfortunately without quantification. Results of liver biopsy were obtained in 4 patients. None of the patients experienced complications after liver biopsy. The mean modified hepatic activity index (MHAI) [11] was 8.5/18 (range 5-13/18), and fibrosis score 3.2/6 (range 1-5/6). Patient 5 with MHAI 13/18 and fibrosis score $4 / 6$ was discontinued from treatment and failed to respond, while patient 12 relapsed with MHAI 8/18 and fibrosis score $5 / 6$.

\section{Treatment Results}

Ten patients completed 48 weeks of treatment. Treatment was discontinued in 4 patients because of the side effects and in 2 patients because of the inefficiency with significant side effects (both genotype $1 b$ ). One patient received $90 \mu \mathrm{g}$ from week 30 to the end of treatment because of pancytopenia. EVR was recorded in 9 patients. Although only 10 patients finished 48 weeks of treatment, ETVR was achieved in 13 patients (in 3 patients treatment was discontinued because of the side effects, but they achieved ETVR). SVR was recorded in 9 patients (table 1). Four patients had elevated ALT at the start of treatment, and they all achieved a biochemical response, although 1 of them failed to achieve a virological response. 
Table 1. Individual data of patients

\begin{tabular}{|c|c|c|c|c|c|c|c|c|c|c|c|c|c|}
\hline \multirow{2}{*}{$\begin{array}{l}\mathrm{Pa}- \\
\text { tient }\end{array}$} & \multirow{2}{*}{ Sex } & \multirow{2}{*}{ Age } & \multirow{2}{*}{$\begin{array}{l}\text { Geno- } \\
\text { type }\end{array}$} & \multirow{2}{*}{ HCV-RNA } & \multicolumn{3}{|c|}{ Treatment } & \multirow{2}{*}{$\begin{array}{l}\text { RNA } \\
12 / 24 / 48 \\
\text { week }\end{array}$} & \multirow[t]{2}{*}{ Side effects } & \multirow{2}{*}{$\begin{array}{l}\text { EPO } \\
\text { dose }\end{array}$} & \multirow[t]{2}{*}{ ETVR } & \multirow[t]{2}{*}{ SVR } & \multirow[t]{2}{*}{ TX/outcome } \\
\hline & & & & & $\begin{array}{l}\text { dura- } \\
\text { tion } \\
\text { weeks }\end{array}$ & $\begin{array}{l}\text { original } \\
\text { dose } \\
\mu \mathrm{g}\end{array}$ & $\begin{array}{l}\text { dose } \\
\text { change } \\
\mu \mathrm{g}\end{array}$ & & & & & & \\
\hline 1 & $\mathrm{M}$ & 40 & $1 b$ & $4.32 \times 10^{6}$ & 48 & 135 & & $+1-1-$ & Arthralgia, flu-like & 12,000 & ETVR & SVR & I \\
\hline 2 & $\mathrm{~F}$ & 60 & $1 b$ & $4.14 \times 10^{6}$ & 24 & 135 & & $+/+$ & Pain, pancytopenia & 12,000 & NR & NR & l \\
\hline 3 & $\mathrm{M}$ & 34 & $1 b$ & $1.17 \times 10^{5}$ & 48 & 135 & & $+/-1-$ & Anemia & 4,000 & ETVR & SVR & TX/SVR \\
\hline 4 & $\mathrm{~F}$ & 54 & $1 b$ & pos & 24 & 135 & & $-1-1-$ & Arthralgia, flu-like, pancytopenia & 12,000 & ETVR & relapse & $\mathrm{TX}$ \\
\hline 5 & M & 55 & $3 a$ & pos & 8 & 135 & & $+/+$ & $\begin{array}{l}\text { Motion sickness, flu-like, } \\
\text { arthralgia, rectorrhagia }\end{array}$ & 8,000 & NR & died & 1 \\
\hline 6 & $\mathrm{M}$ & 44 & $1 b$ & $5.22 \times 10^{5}$ & 40 & 180 & & $+/-1-$ & Flu-like, thrombocytopenia & 12,000 & ETVR & relapse & $\mathrm{TX}$ \\
\hline 7 & $\mathrm{M}$ & 62 & $1 b$ & $2.27 \times 10^{4}$ & 33 & 135 & & $-1-1-$ & Endocarditis, anemia & 12,000 & ETVR & SVR & TX/SVR \\
\hline 8 & $\mathrm{M}$ & 56 & $1 b$ & $4.58 \times 10^{4}$ & 48 & 180 & 135 & $-1-1-$ & Pain, anemia & 12,000 & ETVR & SVR & $\begin{array}{l}\text { TX/graft- } \\
\text { ectomy/SVR }\end{array}$ \\
\hline 9 & $\mathrm{~F}$ & 38 & $3 a$ & $7.38 \times 10^{5}$ & 48 & 135 & & $-1-1-$ & Anemia & 12,000 & ETVR & SVR & TX/SVR \\
\hline 10 & $\mathrm{M}$ & 56 & $1 b$ & pos & 48 & 135 & & $-/-1-$ & Myalgia, flu-like, cough & 12,000 & ETVR & SVR & TX/SVR \\
\hline 11 & M & 56 & $1 b$ & $7.78 \times 10^{6}$ & 48 & 135 & 90 & $-/-/-$ & Arthralgia, myalgia, anemia & 12,000 & ETVR & SVR & TX/SVR \\
\hline 12 & $\mathrm{~F}$ & 40 & $3 a$ & $7.65 \times 10^{5}$ & 36 & 135 & & $-1-1-$ & Arthralgia, anemia & 12,000 & ETVR & relapse & $\mathrm{TX}$ \\
\hline 13 & M & 39 & $1 \mathrm{~b}$ & $4.68 \times 10^{5}$ & 48 & 135 & 90 & $+1-1-$ & Flu-like, myalgia & 12,000 & ETVR & relapse & I \\
\hline 14 & $\mathrm{M}$ & 60 & $2 \mathrm{a}$ & pos & 48 & 135 & & $-/-1-$ & Anemia & 8,000 & ETVR & SVR & I \\
\hline 15 & $\mathrm{~F}$ & 43 & $1 b$ & pos & 48 & 135 & & $-1-1-$ & Anemia & n.a. & ETVR & SVR & l \\
\hline 16 & $\mathrm{M}$ & 62 & $1 b$ & $4.44 \times 10^{6}$ & 48 & 135 & & $+/+/+$ & Myalgia, anemia & 12,000 & $\mathrm{NR}$ & NR & I \\
\hline
\end{tabular}

$\mathrm{ETVR}=$ End-of-treatment virological response; $\mathrm{NR}=$ no response; $\mathrm{SVR}=$ sustained virological response; $\mathrm{EPO}=$ erythropoietin; $. \mathrm{a} .=$ not available; $\mathrm{TX}=$ renal transplantation; pos $=$ positive.

Two patients whose treatment was initiated by infectologists had started with $180 \mu \mathrm{g}$ of PEG-IFN- $\alpha_{2 \mathrm{a}}$ weekly. The treatment dose was reduced in 1 patient after 12 weeks of treatment in collaboration with the nephrologist, while 1 patient developed severe thrombocytopenia which demanded two thrombocyte transfusions and treatment cessation after 40 weeks of therapy.

Nine patients ( 2 of them non-responders) received an allograft from a deceased donor 9 months to 3 years after the end of treatment with PEG-IFN- $\alpha_{2 \mathrm{a}}$. They were treated with a triple immunosuppressive protocol (cyclosporine A, mycophenolate mofetil and steroids) and daclizumab induction. One patient underwent graftectomy after transplantation because of the renal vein thrombosis. Six other patients who achieved ETVR remained HCV-RNA-negative after renal transplantation (mean follow-up of 25 months, range 4-32).

\section{Side Effects}

The most common side effect recorded in 12 patients was anemia requiring transfusion in 1 patient, and increased weekly dose of erythropoietin (4,000-12,000 IU, average $10,933 \mathrm{IU}$ ) in other patients. Hemoglobin levels before treatment ranged from 91 to $129 \mathrm{~g} / \mathrm{l}$ (mean 107, median 112). During treatment, hemoglobin ranged from 65 to $125 \mathrm{~g} / \mathrm{l}$ (mean 95, median 102). A flu-like syndrome was documented in 6 , myalgia in 4 , and arthralgia in 5 patients. Rectorrhagia, endocarditis and severe cough were recorded in 1 patient each. One patient, who failed to respond to treatment, had developed severe arthralgia, rectorrhagia and motion sickness. He died 5 months later after amputation of a lower limb because of the severe vascular insufficiency complicated with sepsis, what was not associated with PEG-IFN- $\alpha_{2 a}$ treatment.

\section{Discussion}

$\mathrm{HCV}$ infection is a well-known adverse prognostic factor for survival in patients with ESRD $[12,13]$. In a meta-analysis which included 2,000 patients, HCV infection was associated with an increased risk of mortality of 1.57 compared to uninfected dialysis patients [2]. Chronic HCV infection in patients with ESRD may slowly progress to serious hepatic lesions including cirrhosis and hepatocellular carcinoma. Patients are even more endan- 
gered with the use of immunosuppressive drugs after renal transplantation which further suppresses the already impaired immunological system, thus enabling viral replication and enhancing liver damage [14].

Pereira et al. [15] evaluated the relative risk of death among patients with positive anti-HCV who receive a renal allograft with those remaining on the waiting list. Transplantation was associated with enhanced survival compared to continued dialysis $(\mathrm{p}<0.0001)$. According to the current knowledge and our experience, the possible unfavorable consequence of renal transplantation on the course of HCV infection is balanced by the long-term favorable effect on survival in ESRD. Thus, anti-HCV-positive status alone should not be a contraindication for renal transplantation.

Treatment of chronic HCV infection should be carried out before renal transplantation to avoid possible graft rejection associated with the use of IFN. However, conventional IFN monotherapy leads to SVR rates of up to $40 \%$ of dialysis patients [4]. Relatively poor outcome and severe side effects discourage use of IFN in treatment of chronic $\mathrm{HCV}$ infection in dialysis patients. PEG-IFN- $\alpha_{2 a}$ was found to be more effective than standard IFN- $\alpha_{2 a}$ in HCV patients [16]. Several papers dealing with efficacy and safety of PEG-IFN- $\alpha_{2 a}$ in dialysis patients were published. One would expect more published material, while chronic HCV infection represents a serious problem in the ESRD population. Reasons for the small number of studies may include the decreasing incidence of HCV in developed countries, and insufficient funds for covering costs of PEG-IFN- $\alpha_{2 \mathrm{a}}$ treatment in developing countries which are still faced with a relatively high prevalence of HCV.

Thus, the literature on this topic consists predominantly of small clinical trials [17-23] with most of them being of an uncontrolled nature. A meta-analysis performed by Gordon et al. [24] demonstrated SVR in 37\% of patients treated with PEG-IFN- $\alpha_{2 \mathrm{a}}$, with a discontinuation rate of $28 \%$. A recent meta-analysis performed by Fabrizi et al. [25] included 16 clinical trials with 254 patients. Only 5 studies were controlled. SVR was $33 \%$ with a drop-out rate of $23 \%$.

In the present paper we demonstrated results of PEGIFN- $\alpha_{2 \mathrm{a}}$ treatment of dialysis patients in Croatia. PEGIFN- $\alpha_{2 \mathrm{a}}$ had limited efficacy, while a significant proportion of patients discontinued treatment because of side effects and lack of response. SVR did not significantly differ from the ETVR. In comparison with data based on meta-analyses, we have recorded better SVR (56.2\%) but a higher rate of patients who failed to finish treatment
$(37.5 \%)[24,25]$, probably because of the very long dialysis history of our patients.

Most of our patients had already spent more than 10 years (even 28 years) on dialysis, what may explain the high proportion of patients with arthralgia and impaired motion after treatment with PEG-IFN- $\alpha_{2 a}$ compared with other studies. Although we had results for only 4 liver biopsies, 2 of the non-responders were patients with a high fibrosis score (4 and 5/6).

There was no statistically significant difference in SVR among genders. Patients younger than 40 years all achieved SVR, what is in concordance with previously recorded results [26]. Lower baseline HCV-RNA was not associated with an outcome of PEG-IFN- $\alpha$ therapy in hemodialysis patients as was concluded by Gordon et al. [24].

Nine patients received a renal allograft, and those who achieved ETVR remained HCV-RNA-negative after transplantation (2 patients were non-responders). This data supports the treatment of all HCV-RNA-positive patients who are candidates for renal transplantation. Pegeaux et al. [27] reported on favorable results of the treatment of renal transplant recipients with PEG-IFN$\alpha_{2 \mathrm{a}}$. Eight patients received PEG-IFN- $\alpha_{2 \mathrm{a}}$ alone or in combination with ribavirin. SVR was achieved in 4 patients. No patient developed rejection episodes during or after PEG-IFN- $\alpha_{2 \mathrm{a}}$ therapy. One patient experienced hemolytic uremic syndrome which resulted in graft loss. Further studies are needed to support these important results.

The main disadvantage of our study is its retrospective nature and lack of uniform approach to treatment. Some patients were treated by nephrologists, while some of them were under the follow-up of infectologists. However, this could also be an advantage, since our results demonstrate that in cases when infectologists treat this group of patients, nephrologists should be closely involved in follow-up while dialysis patients significantly differ from other HCV-positive patients and need closer supervision.

\section{Conclusion}

According to our experience, PEG-IFN- $\alpha_{2 a}$ has limited efficacy in dialysis patients, while a significant proportion of patients discontinued treatment because of the side effects. SVR did not significantly differ from the ETVR. Ribavirin may improve results of treatment with PEG-IFN- $\alpha_{2 a}$ in dialysis patients. Additional studies with long-term follow-up are needed to determine the optimal treatment of $\mathrm{HCV}$ infection in the dialysis population. 


\section{References}

$\rightarrow 1$ Kes P, Basic-Jukic N: Hepatitis C in dialysed patients - what is the current optimal treatment? Kidney Blood Pres Res 2007;30:156161.

-2 Fabrizi F, Martin P, Dixit V, et al: Meta-analysis: effect of hepatitis $C$ virus infection on mortality in dialysis. Aliment Pharmacol Ther 2004;20:1271-1277.

3 Knoll GA, Tankersley MR, Lee JY, et al: The impact of renal transplantation on survival in hepatitis C-positive end-stage renal disease patients. Am J Kidney Dis 1997;29:608614.

4 Russo MW, Goldsweig CD, Jacobson IM, Brown RS Jr: Interferon monotherapy for dialysis patients with chronic hepatitis C: an analysis of the literature on efficacy and safety. Am J Gastroenterol 2003;98:1610-1615.

5 Alavian SM, Tabatabei SV: Conventional interferon- $\alpha$ therapy of chronic hepatitis $\mathrm{C}$ in patients with end-stage renal disease, six versus twelve months? A meta-analysis. Int J Nephrol Urol 2009;1:4-13.

6 Glue P, Fang JW, Rouzier-Panis R, et al: Pegylated interferon- $\alpha_{2 b}$ : pharmacokinetics, pharmacodynamics, safety and preliminary efficacy data. Hepatitis C Intervention Therapy Group. Clin Pharmacol Ther 2000;68: 556-567.

7 Crotty S, Maag D, Arnold JJ, et al: The broadspectrum antiviral ribonucleoside ribavirin is an RNA virus mutagen. Nat Med 2000;6: 1375-1379.

8 Ning Q, Brown D, Parodo J, et al: Ribavirin inhibits viral-induced macrophage production of TNF, IL-1, the procoagulant fgl2 prothrombinase and preserves Th1 cytokine production but inhibits Th2 cytokine response. J Immunol 1998;160:3487-3493.

$\checkmark 9$ Dixit, NM, Layden-Almer, JE, Layden, TJ, Perelson, AS: Modelling how ribavirin improves interferon response rates in hepatitis C virus infection. Nature 2004;432:922-924.
10 Carriero D, Fabrizi F, Uriel AJ, Park J, Martin P, Dietrich DT: Treatment of dialysis patients with chronic hepatitis $\mathrm{C}$ using pegylated interferon and low-dose ribavirin. Int J Artif Organs 2008;31:295-302.

11 Knodell RG, Ishak KG, Black WC, et al: Formulation and application of a numerical scoring system for assessing histological activity in asymptomatic chronic active hepatitis. Hepatology 1981;1:431-435.

12 Fissell RB, Bragg-Gresham JL, Woods JD, et al: Patterns of hepatitis $C$ prevalence and seroconversion in hemodialysis units from three continents: the DOPPS. Kidney Int 2004;65:2335-2342.

13 Stehman-Breen CO, Emerson S, Gretch D Johnson RJ: Risk of death among chronic dialysis patients infected with hepatitis $\mathrm{C}$ virus. Am J Kidney Dis 1998;32:629-634.

14 Maluf DG, Fisher RA, King AL, et al: Hepatitis $\mathrm{C}$ virus infection and kidney transplantation: predictors of patient and graft survival. Transplantation 2007;83:853-857.

15 Pereira BJ, Natov SN, Bouthot BA, et al: Effect of hepatitis $C$ infection and renal transplantation on survival in end-stage renal disease. Kidney Int 1998;53:1374-1381.

16 Liu CH, Liang CC, Lin JW, et al: Pegylated interferon- $\alpha_{2 a}$ versus standard interferon$\alpha_{2 a}$ for treatment-naive dialysis patients with chronic hepatitis C: a randomized study. Gut 2008;57:525-530.

17 Akhan SC, Kalender B, Ruzgar M: The response to pegylated interferon- $\alpha_{2 a}$ in haemodialysis patients with hepatitis $\mathrm{C}$ infection. Infection 36:341-344.

18 Alsaran K, Sabry A, Shaheen N: Pegylated interferon- $\alpha_{2 \mathrm{a}}$ for treatment of chronic $\mathrm{HCV}$ infection in hemodialysis patients: a single Saudi center experience. Int Urol Nephrol 2010 (in press).

19 Ayaz C, Celen MK, Yuce UN, Geyik MF: Efficacy and safety of pegylated-interferon- $\alpha_{2}$ in hemodialysis patients with chronic hepatitis C. World J Gastroenterol 2008;14:255259.
20 Casanovas Taltavull T, Baliellas Cornellas C, Cruzado Garrit JM: Results of hepatitis C virus treatment in patients on hemodialysis: data from published meta-analyses in 2008. Transplant Proc 2009;41:2082-2084.

21 Dzekova P, Asani A, Selim G, et al: Longterm follow-up of sustained viral response after treatment of hepatitis $\mathrm{C}$ with pegylated interferon- $\alpha_{2 a}$ in hemodialysis patients. Int J Artif Organs 2009;32:180-184.

22 Kose S, Gurkan A, Akman F, Kelesoglu M, Uner U: Treatment of hepatitis C in hemodialysis patients using pegylated interferon$\alpha_{2 \mathrm{a}}$ in Turkey. J Gastroenterol 2009;44:235238 .

23 Ucmak H, Kokoglu OF, Hosoglu S, Dogan E, Sayarlioglu H, Kuzan H, Isik IO: Long-term efficacy of pegylated interferon- $\alpha_{2 a}$ in HCVpositive hemodialysis patients. Ren Fail 2008;30:227-232

24 Gordon CE, Uhlig K, Lau J, Schmid CH, Levey AS, Wong WB: Interferon treatment in hemodialysis patients with chronic hepatitis $C$ virus infection: a systematic review of the literature and meta-analysis of treatment efficacy and harms. Am J Kidney Dis 2008; 51:263-277.

25 Fabrizi F, Dixit V, Messa P, Martin P: Pegylated interferon monotherapy of chronic hepatitis $\mathrm{C}$ in dialysis patients: meta-analysis of clinical trials. J Med Virol 2010;82:768775 .

26 Alavian SM, Tabatabei SV: Meta-analysis of factors associated with sustained viral response in patients on hemodialysis treated with standard or pegylated interferon for hepatitis C infection. Iran J Kidney Dis 2010; 4:181-194.

27 Pegeaux GP, Hilleret MN, Garrigues V, Bismuth M, Audin-Mamlouk H, Zarski JP, Mourad G: Pegylated interferon- $\alpha$-based treatment for chronic hepatitis $\mathrm{C}$ in renal transplant recipients: an open pilot study. Transplant Int 2009;22:562-567. 